\title{
Provenancing the first obsidian artefact discovered in Belarus
}

\author{
Vitali Asheichyk ${ }^{1}$, Yaroslav Kuzmin ${ }^{2,3, *}$, Michael D. Glascock ${ }^{4}$, \\ Mikola Kryvaltsevich ${ }^{1}$, Evgeny Girya ${ }^{5} \&$ Aliaksandr Vashanau $^{1}$
}

Geochemical analysis of the first obsidian artefact discovered in Belarus reveals its source to be the Trans-Caucasus, rather than the expected Carpathian source for prehistoric obsidian in Eastern Europe.

Keywords: Belarus, Neolithic, Bronze Age, obsidian, XRF

Recent provenance studies of obsidian artefacts from Central and Eastern Europe have identified the Carpathian Mountains as a major primary source area (e.g. Biró 2006; Rosania et al. 2008). Obsidian from other sources in the Caucasus region and Anatolia (Biagi et al. 2014) is rarely found. Here we report the first find of an obsidian artefact in Belarus, and its geochemical analysis.

In 2001, a fragment of obsidian (Figure 1) was found near Navasiolki Village in the Brest Province, Belarus (coordinates 52 $01^{\prime} 43^{\prime \prime N}, 24^{\circ} 22^{\prime} 16^{\prime \prime} \mathrm{E}$ ). Subsequent survey from 2014-2017 revealed artefacts on the surface close to the findspot and in test-pits; the site was named Navasiolki 6. The assemblage comprises ceramic and lithic artefacts (Figure 2) estimated to date from the Late Neolithic, Bronze Age and Early Iron Age (third millennium $\mathrm{BC}$ to the $\mathrm{BC} / \mathrm{AD}$ boundary). The close proximity of archaeological materials to the obsidian artefact rules out the possibility that the item is a hoax.

The artefact is an unmodified flake, or primary spall, of red-black mottled obsidian, measuring $43 \times 33 \times 19 \mathrm{~mm}$ (Figure 1). It has cortex remaining on its dorsal side, and it was not a river pebble. The flaking negatives are similar to those that result from striking obsidian without suitable platforms. The prehistoric person may have attempted to smash the raw obsidian into a sub-rounded form using a hard hammerstone.

1 Institute of History, National Academy of Sciences of Belarus, Akademichnaya Street 1, Minsk 220072, Belarus

2 Sobolev Institute of Geology \& Mineralogy, Siberian Branch of the Russian Academy of Sciences, Koptyug Avenue 3, Novosibirsk 630090, Russia

3 Laboratory of Mesozoic \& Cenozoic Continental Ecosystems, Tomsk State University, Lenin Avenue 36, Tomsk 634050, Russia

4 Archaeometry Laboratory, Research Reactor Center, 1513 Research Park Drive, University of Missouri, Columbia, MO 65211, USA

5 Institute for Material Culture History, Russian Academy of Sciences, Dvortsovaya Embankment 18, St Petersburg 191186, Russia

* Author for correspondence (Email: kuzmin@fulbrightmail.org)

(C) Antiquity Publications Ltd, 2018

ANTIQUITY 92 365, e4 (2018): 1-7

https://doi.org/10.15184/aqy.2018.220 


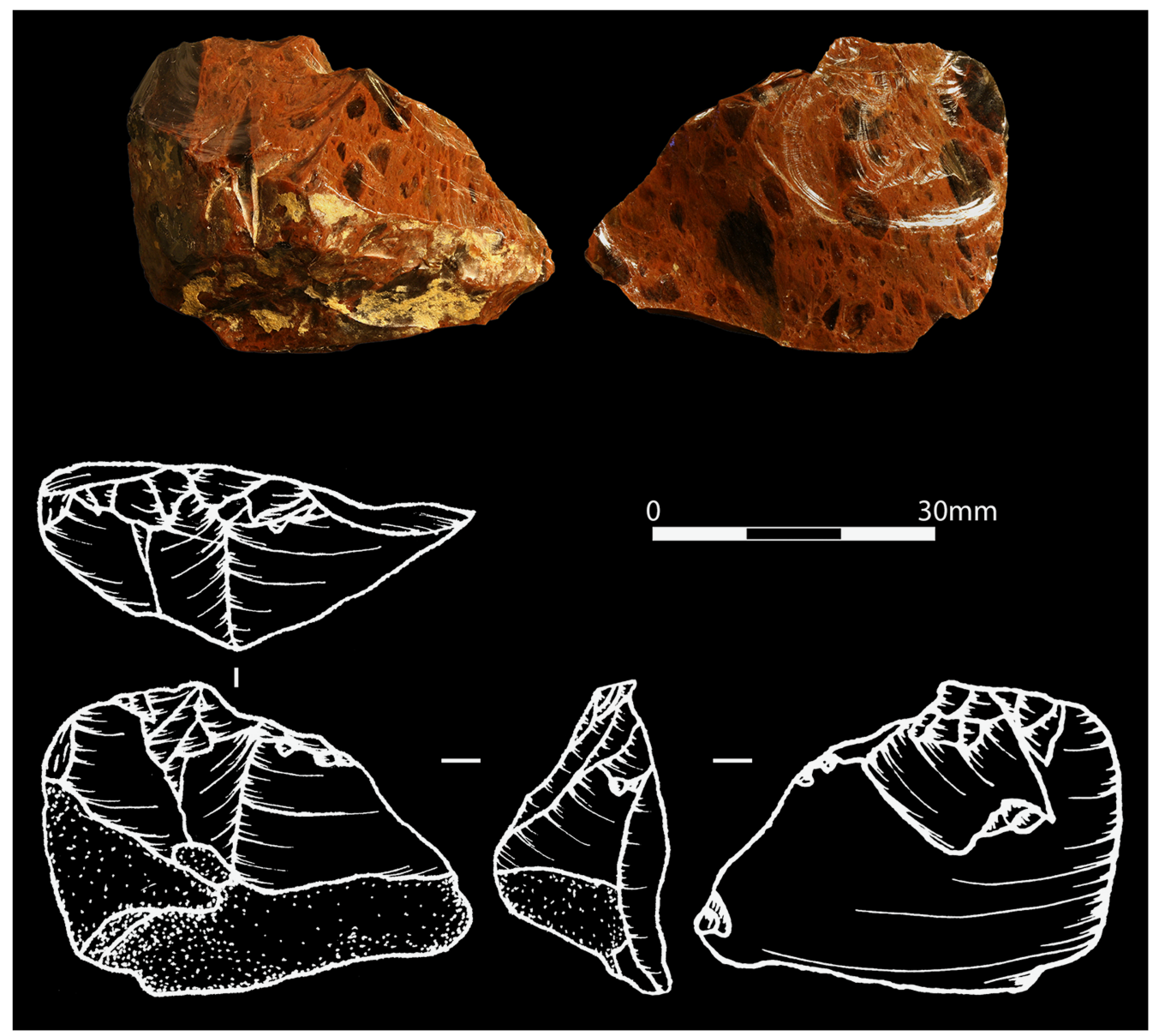

Figure 1. Obsidian artefact from the Navasiolki 6 site (figure by authors).

The artefact was examined using X-ray fluorescence (XRF) at the Archaeometry Laboratory in the Research Reactor Center of the Missouri University, using a ThermoScientific ARL Quantx Energy-Dispersive XRF spectrometer, following standard procedure (Glascock et al. 2016). This established the content of magnesium (Mn), iron $(\mathrm{Fe})$, zinc $(\mathrm{Zn})$, rubidium $(\mathrm{Rb})$, strontium $(\mathrm{Sr})$, yttrium $(\mathrm{Y})$, zirconium $(\mathrm{Zr})$, niobium $(\mathrm{Nb})$ and thorium (Th) (Table 1). Statistical grouping, based on bivariate plots, and on cluster and discriminant classification analyses, was performed by using the GAUSS software (available at: http://archaeometry.missouri.edu/datasets/GAUSS_Download. html), to indicate the source of the obsidian with a 90 per cent probability (see Glascock et al. 1998).

Comparison of the Navosiolki 6 artefact's geochemical composition with possible primary sources in the Carpathian Mountains and the Caucasus region (Figure 3) shows that the obsidian artefact originates from the Pokr Arteni area in Armenia, Trans-Caucasus 


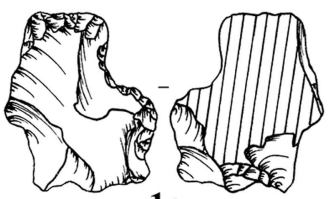

1a

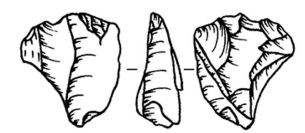

2a

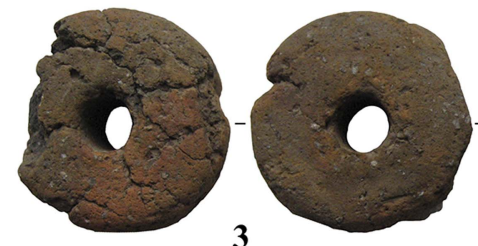

3
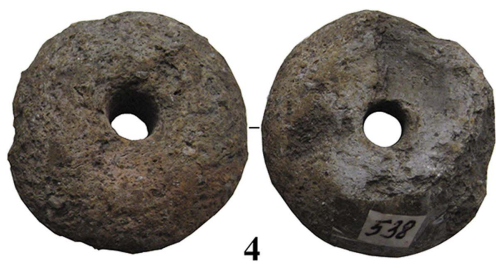

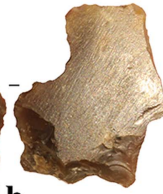

$1 \mathrm{~b}$

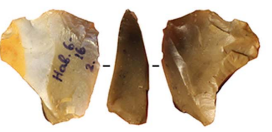

2b
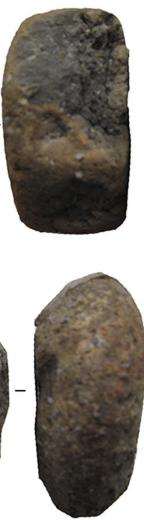
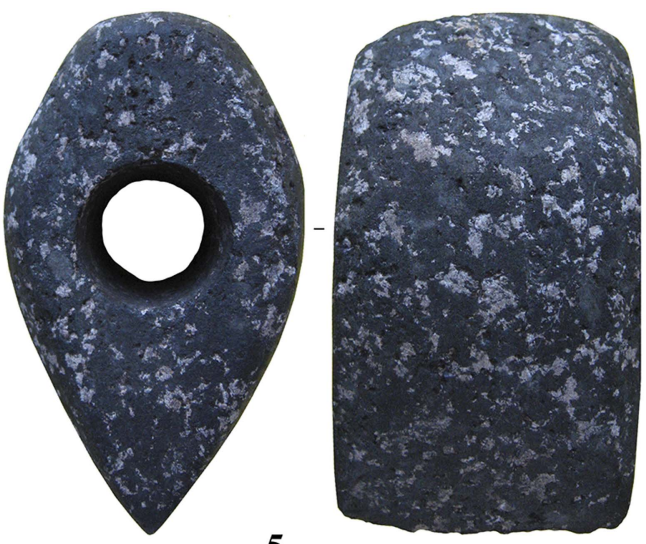

5
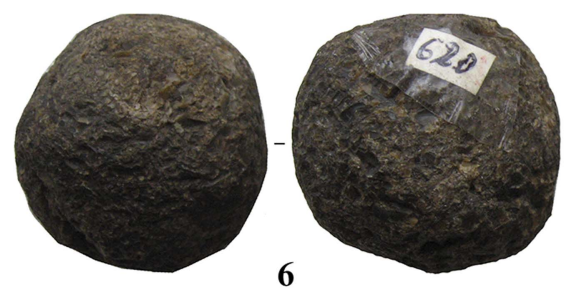

0

$30 \mathrm{~mm}$

Figure 2. Selected artefacts from the Navasiolki 6 site: 1) fragment of a fint ground item with secondary retouch (a: drawing; b: photograph); 2) flint bipolar piece (a: drawing; b: photograph); 3-4) clay spindle whorls; 5) shaft-hole axe; 6) flint hammerstone (figure by authors).

Table 1. Composition (parts per million) of elements for the Navasiolki 6 obsidian compared to the Pokr Arteni source (Glascock 2018)

Element Navasiolki 6 artefact Means and standard deviations for Pokr Arteni source $(n=40)$

\begin{tabular}{lcc}
$\mathrm{Mn}$ & 618 & $602 \pm 113$ \\
$\mathrm{Fe}$ & 4630 & $4582 \pm 282$ \\
$\mathrm{Zn}$ & 25 & $32 \pm 10$ \\
$\mathrm{Rb}$ & 121 & $131 \pm 8$ \\
$\mathrm{Sr}$ & 32 & $25 \pm 7$ \\
$\mathrm{Y}$ & 22 & $23 \pm 3$ \\
$\mathrm{Zr}$ & 90 & $80 \pm 9$ \\
$\mathrm{Nb}$ & 29 & $32 \pm 3$ \\
$\mathrm{Th}$ & 15 & $15 \pm 2$ \\
\hline
\end{tabular}

(Chataigner \& Gratuze 2014: 28). The distance from source to the Navasiolki 6 site is approximately $1990 \mathrm{~km}$ (Figure 4 ). The obsidian artefact therefore probably represents a Late Neolithic or Bronze Age 'exotic' import into western Belarus. 


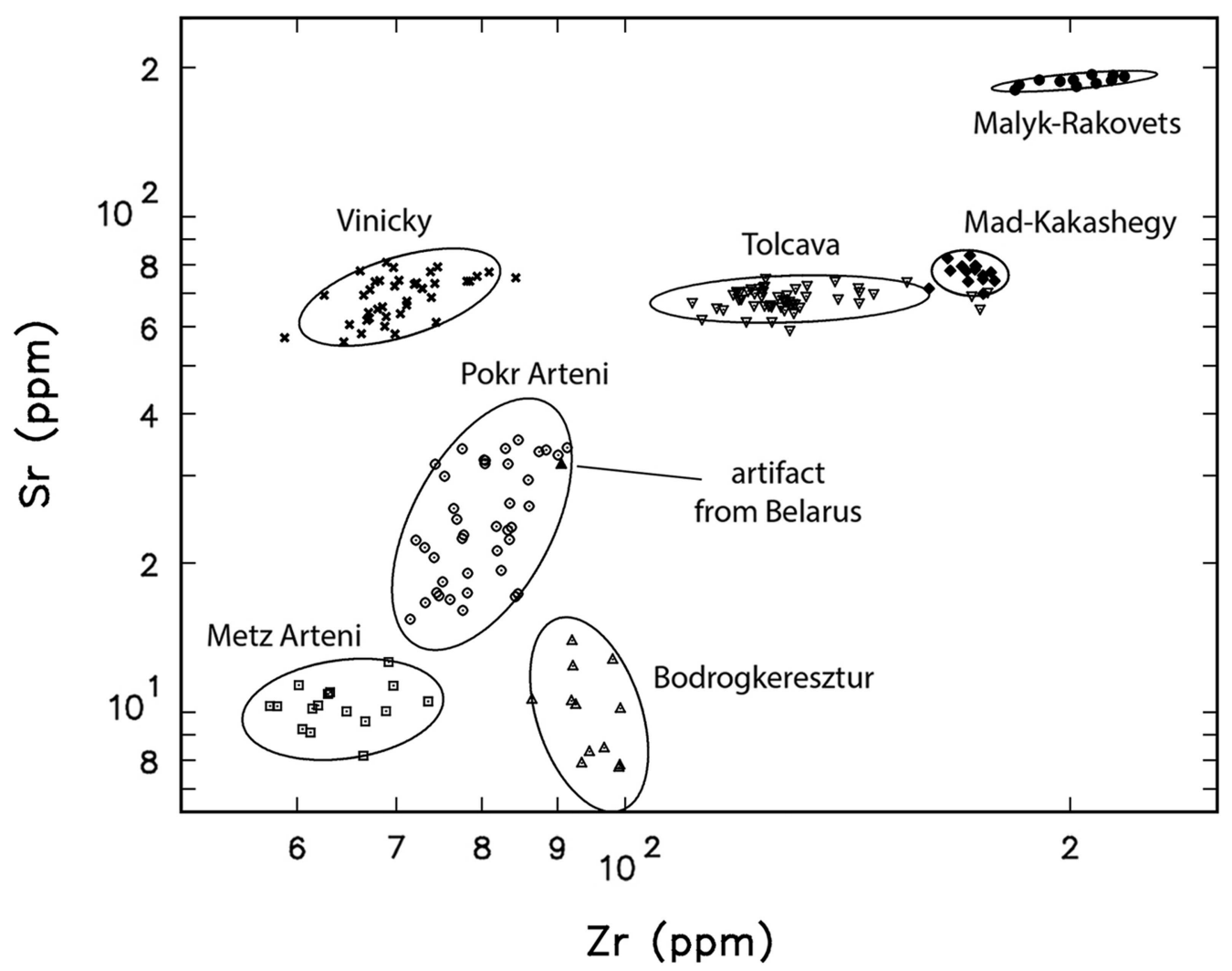

Figure 3. Bivariate plot of XRF (zirconium vs. strontium) for the Navasiolki 6 artefact, and for some Carpathian and Caucasian primary obsidian sources; ellipses are 90 per cent confidence areas (figure by authors).

The provenancing of this find is important, as no obsidian from the Caucasus has been found so far north and west; in this part of Eastern Europe, only Carpathian obsidian - at distances up to approximately $500 \mathrm{~km}$ from the primary source-is known within prehistoric assemblages (Figure 5). Although the Krzeczów site in north-western Ukraine yielded Carpathian obsidian (from the Brehov-Vinićky region in Slovakia; Figure 5) (Hughes et al. 2018), it was not detected farther north and east.

Prehistoric obsidian artefacts are very rare outside the Carpathian 'sphere' of Central/ Eastern European distribution. Some were found in the lower course of the Dnieper River in south-eastern Ukraine, and are associated with the Bronze Age Yamnaya and Catacomb cultures (Razumov 2011). The northern Caucasus, Trans-Caucasus and central Anatolia have been identified as sources of obsidian for the Neolithic sites of Semenovka 1 and Lysa Gora (Biagi et al. 2014) (Figure 4). These discoveries changed the view that Carpathian sources were the only suppliers of obsidian to this part of Europe.

Identification of sources of obsidian can supply new information about human contact, exchange and migration that cannot be established by other methods or archaeological data alone (Williams-Thorpe 1995: 234-35). The artefact from Belarus provides an excellent (C) Antiquity Publications Ltd, 2018 


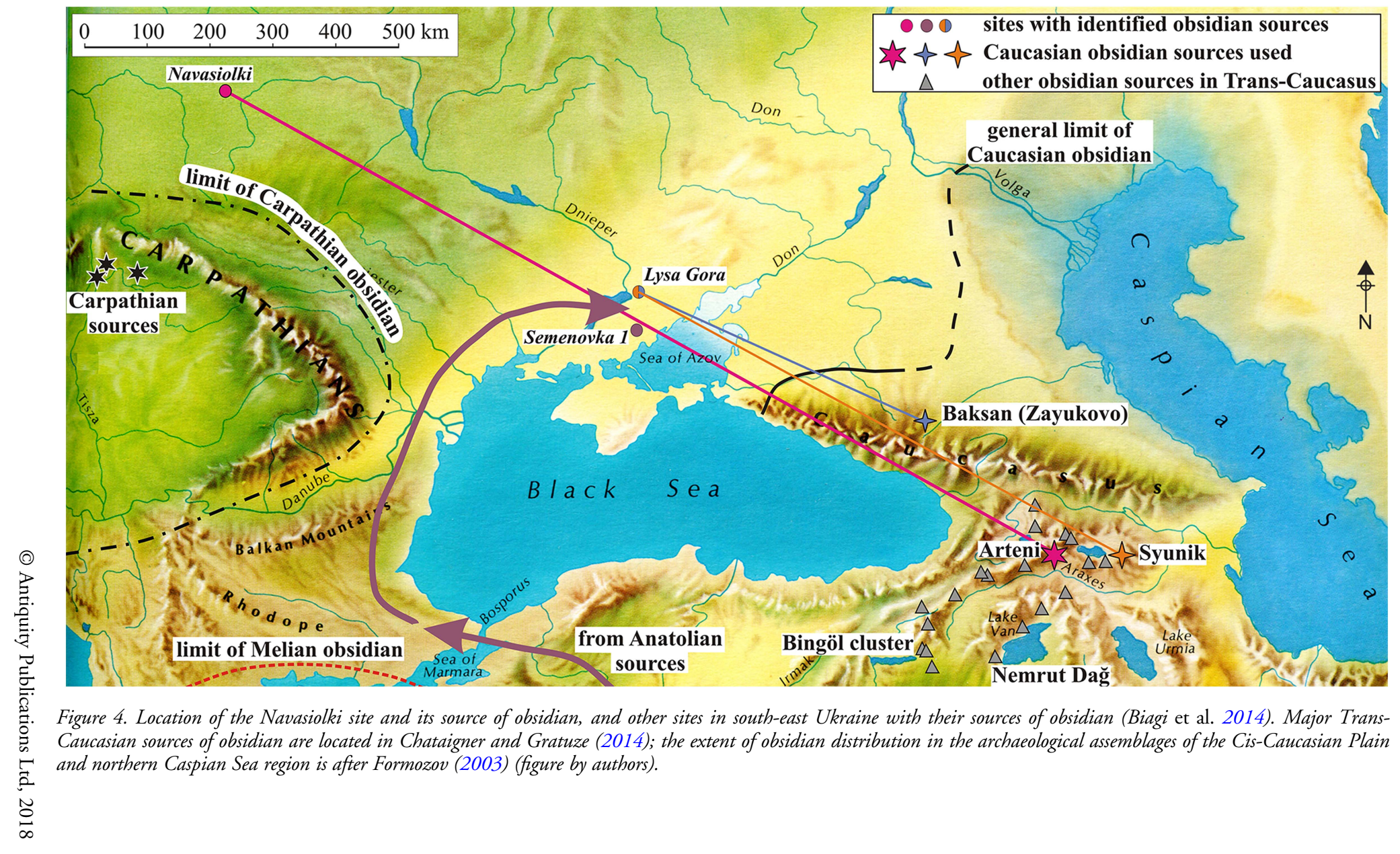

\section{Project Gallery}




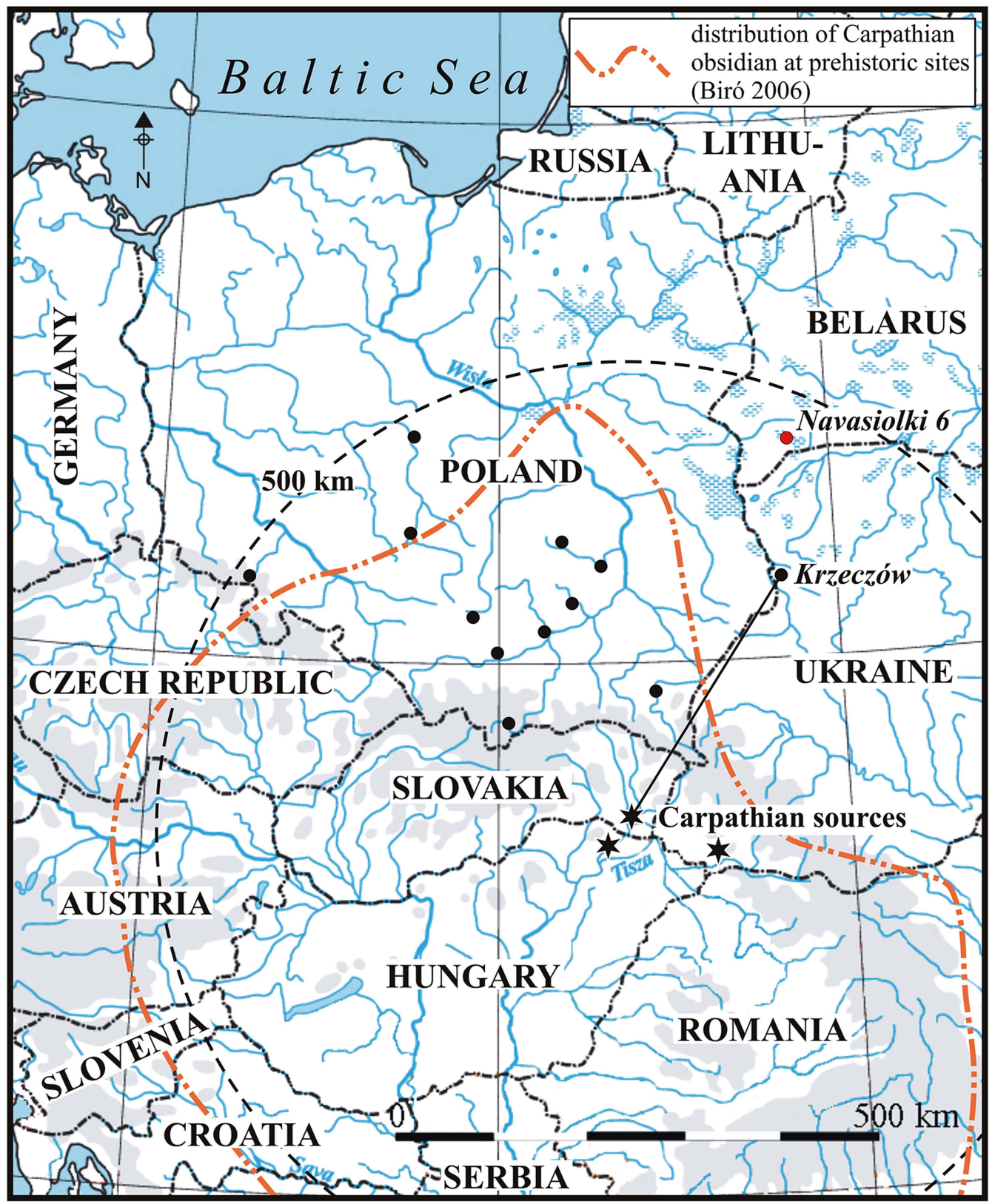

Figure 5. Distribution of Carpathian obsidian in Poland and neighbouring regions (after Biró 2006). Black circles indicate sites in Poland and Ukraine with obsidian from Carpathian sources (Hughes et al. 2018) (figure by authors). 
illustration of an unexpected connection between this region of prehistoric Eastern Europe and the Caucasus.

\section{References}

Biagi, P., B. Gratuze, D.V. Kiosak, O.V. Tubolzev \& Z.H. Popandopulo. 2014. The Neolithic obsidians from southeastern Ukraine: first characterization and provenance determination. Anadolu/Anatolia 40: 1-20.

Biró, K.T. 2006. Carpathian obsidians: myth and reality, in J. Pérez-Arantegui (ed.) Proceedings of the $34^{\text {th }}$ International Symposium on Archaeometry: 267-77. Zaragoza: Institución 'Fernando el Católico'.

Chataigner, C. \& B. Gratuze. 2014. New data on the exploitation of obsidian in the southern Caucasus (Armenia, Georgia) and eastern Turkey. Part 1: source characterization. Archaeometry 56: 25-47. https://doi.org/10.1111/arcm.12006

Formozov, A.A. 2003. Drevneishie etapy istorii evropeiskoi Rossii. Moscow: Nauka (in Russian).

GLASCOCK, M.D. 2018. Obsidian database of the Archaeometry Laboratory at the University of Missouri Research Reactor (unpublished manuscript).

Glascock, M.D., G.E. Braswell \& R.H. Cobean. 1998. A systematic approach to obsidian source characterization, in M.S. Shackley (ed.) Archaeological obsidian studies: method and theory: 15-65. New York: Springer.
Glascock, M.D., A.W. Barker, S.B. Crisan, F. Drasovean, M. Gligor \& D. Negrei. 2016. Sourcing obsidian artifacts from archaeological sites in central and western Romania by X-ray fluorescence. Analele Banatului, S.N. Archaeologie -Istorie 24: 75-85.

Hughes, R.E., D.H. Werra \& Z. Sulgostowska. 2018. On the sources and uses of obsidian during the Paleolithic and Mesolithic in Poland. Quaternary International 468: 84-100. https://doi.org/10.1016/j.quaint.2017.11.013

Razumov, S.M. 2011. Flint artefacts of northern Pontic populations of the Early and Middle Bronze Age: 3200-1600 BC (based on burial materials). Poznań: Adam Mickiewicz University.

Rosania, C.N., M.T. Boulanger, K.T. Biró, S. Ryzhov, G. Trnka \& M.D. Glascock. 2008. Revisiting Carpathian obsidian. Antiquity Project Gallery 82(318). Available at: http://www.antiquity.ac.uk/projgall/rosania318 (accessed 20 September 2018).

Williams-Thorpe, O. 1995. Obsidian in the Mediterranean and Near East: a provenancing success story. Archaeometry 37: 217-48. https://doi.org/10.1111/j.1475-4754.1995. tb00740.x 